\section{Cureus}

Received 05/23/2019

Review began 05/28/2019

Review ended 05/31/2019

Published 07/01/2019

\section{(c) Copyright 2019}

Chaudhary et al. This is an open access article distributed under the terms of the Creative Commons Attribution License CC-BY 3.0., which permits unrestricted use, distribution, and reproduction in any medium, provided the original author and source are credited.

\title{
Association of Obesity Indicators with Hypertension in Type 2 Diabetes Mellitus Patients
}

Ghulam Mohyud Din Chaudhary ${ }^{1}$, Asim Tameez Ud Din ${ }^{2}$, Farooq Mohyud Din Chaudhary ${ }^{3}$, Azfar Tanveer ${ }^{1}$, Khaleeq H. Siddiqui ${ }^{4}$, Asma Tameez Ud Din ${ }^{1}$, Noman A. Chaudhary ${ }^{5}$, Sana Mohyud Din Chaudhary ${ }^{6}$, Ahsan Tameez-ud-din ${ }^{2}$, Faisal Nawaz ${ }^{7}$

1. Internal Medicine, Nishtar Medical University \& Hospital, Multan, PAK 2. Internal Medicine, Rawalpindi Medical University, Rawalpindi, PAK 3. Gastroenterology, Nishtar Medical University \& Hospital, Multan, PAK 4. Internal Medicine, NewYork-Presbyterian Queens, Flushing, USA 5. Surgery, Rawalpindi Medical University, Rawalpindi, PAK 6. Internal Medicine, Combined Military Hospital Lahore Medical College \& Institute of Dentistry, Lahore, PAK 7. Gastroenterology, Good Hope Hospital, University Hospitals Birmingham, Birmingham, GBR

$\square$ Corresponding author: Farooq Mohyud Din Chaudhary, farooqmdc@gmail.com Disclosures can be found in Additional Information at the end of the article

\section{Abstract}

Objectives: To study the association of waist circumference (WC), waist to hip ratio (WHR) and body mass index (BMI) with hypertension in type 2 diabetes mellitus (DM) patients in a tertiary care hospital.

Methods: The anthropometric measures of patients were recorded in the Diabetic Outdoor of Nishtar Hospital Multan from 2013 to 2018 after taking approval from the Institutional Ethical Review Committee. All patients were evaluated in detail after obtaining informed consent. Data was entered and analyzed in SPSS version 20 (IBM Corp., Armonk, NY, USA).

Results: Data of 4556 type 2 DM patients, 2549 (55.9\%) females, and 2007 (44.1\%) males, was analyzed. Mean age of the study population was 47.72 years. Mean age of females was 47.32 years, while of males was 48.23 years. A total of 3393 (74.5\%) of the patients had hypertension, 1912 females and 1481 males. The mean systolic blood pressure (SBP) was $130.84 \mathrm{mmHg}$, while the mean diastolic blood pressure (DBP) was $82.65 \mathrm{mmHg}$. Mean WC was $102.85 \mathrm{~cm}$. Mean hip circumference was $100.33 \mathrm{~cm}$. Mean weight was $66.93 \mathrm{~kg}$. Mean height was $1.59 \mathrm{~m}$. Mean WHR was 1.02. Mean BMI was $26.37 \mathrm{~kg} / \mathrm{m} 2$. Obesity (BMI >27 kg/m2) was found in 1,891 (41.5\%) of patients. Central obesity was found in $80.7 \%$ and $94.7 \%$ of type 2 DM patients according to the WC and WHR cutoff, respectively. Hypertension was significantly associated with all the obesity indicators $(\mathrm{p}<0.001)$. Type $2 \mathrm{DM}$ patients with a high WHR were more likely to be hypertensive as compared to those with normal WHR (75\% versus 65\%, odds ratio (OR) 1.6, p<0.001). A higher than normal WC was also significantly associated with hypertension (79\% versus 56\%, OR 2.9, p<0.001). Similarly, obese type 2 DM patients with a BMI $>27 \mathrm{~kg} / \mathrm{m} 2$ were more likely to be hypertensive as compared to those with a normal range (18.5 to $22.9 \mathrm{~kg} / \mathrm{m} 2) \mathrm{BMI}(83.1 \%$ versus $64.4 \%$, OR 2.7, $\mathrm{p}<0.001)$.

Conclusion: Diabetes is more prevalent in females and middle-aged people. Hypertension and obesity are two very common comorbidities of diabetes. Hypertension is strongly associated with all the parameters (WC, WHR, and BMI) of obesity. 
Categories: Endocrinology/Diabetes/Metabolism

Keywords: type 2 diabetes mellitus, hypertension, obesity, waist circumference, waist to hip ratio, body mass index

\section{Introduction}

Diabetes mellitus (DM) has emerged as one of the global health issues in recent years. Its prevalence in adults is reported to be $8 \%$ which is expected to rise to $10 \%$ by 2040 . More than $90 \%$ of this population belongs to type 2 DM group [1]. The pathophysiology of Type 2 DM mainly involves insulin resistance. It is associated with multiple cardiovascular and metabolic risk factors [2]. Obesity has emerged as one of the strongly associated modifiable risk factors of type 2 DM owing to its role in insulin resistance. By 2025, there are reports that obesity, which is related to diabetes, would rise to an alarming number of 300 million [3].

Hypertension is another risk factor associated with type $2 \mathrm{DM}$. Its prevalence in diabetic patients is almost double as compared to non-diabetics [4]. The presence of hypertension expedites the development of complications in a diabetic patient like stroke, myocardial infarction, retinopathy, neuropathy, and nephropathy. The concomitant presence of hypertension in a diabetic patient increases the mortality and morbidity of these patients [5].

There are multiple studies evaluating obesity and hypertension as independent risk factors to DM. But the association of obesity and hypertension in a diabetic patient is not widely studied. In this article, we aim to demonstrate the association of different indicators of obesity like waist circumference (WC), waist to hip ratio (WHR), and body mass index (BMI) with hypertension in type 2 DM patients.

\section{Materials And Methods}

This descriptive analytical study was carried out at the Diabetic Outdoor Nishtar Hospital Multan after taking approval from the local Institutional Ethical Committee. After obtaining informed consent, data of 4556 type 2 DM patients presenting to the Diabetes Clinic was collected from 2013 to 2018. The inclusion criteria included all adults of age 18 years or older, who were either previously diagnosed diabetics or newly diagnosed type $2 \mathrm{DM}$. Diabetes was diagnosed according to the following cut-off values; fasting blood sugar (FBS) $>126 \mathrm{mg} / \mathrm{dl}$ and random blood sugar $(\mathrm{RBS})>200 \mathrm{mg} / \mathrm{dL}$. Patients less than 18 years of age, or those who had type $1 \mathrm{DM}$, impaired glucose tolerance, impaired fasting glucose, or gestational DM were excluded from the study. Patient's history, examination findings, and laboratory investigations were evaluated in meticulous detail.

A predesigned performa was used to record the demographic and anthropometric measures of the patients. Hypertension was defined according to American College of Cardiology/American Heart Association (ACC/AHA) guidelines: systolic blood pressure (SBP) $>130 \mathrm{mmHg}$ or diastolic blood pressure (DBP) $>80 \mathrm{mmHg}$ [6]. Body mass index (BMI) was calculated by the formula: weight $(\mathrm{kg}) /$ height(m2). Obesity was defined as BMI $>27 \mathrm{~kg} / \mathrm{m} 2$ according to BMI cutoff for Asians [7]. Central obesity was defined according to the following cut-off values: waist circumference (WC; men $\geqslant 90 \mathrm{~cm}$ and women $\geqslant 80 \mathrm{~cm}$ ) and waist to hip ratio (WHR; men >0.9, women >0.8) [8-9]. The gathered data was entered in SPSS version 20 (IBM Corp., Armonk, NY, USA). Statistical data analysis was performed with chi-square. Statistical significance was determined at $\mathrm{p}<0.05$. Information obtained was then analyzed. Association of hypertension with different demographic variables and obesity parameters was evaluated by calculating the odds ratio (OR). The findings were presented in the form of tables.

\section{Results}




\section{Cureus}

Out of 4556 patients with Type 2 DM, 2549 (55.9\%) were females while 2007 (44.1\%) were males. Mean age of the patients was $47.72 \pm 10.82$ years with a range of $18-95$ years. Mean age of females was $47.32 \pm 10.37$ years, while that of males was $48.23 \pm 11.35$ years.

A total of 3393 (74.5\%) of the patients had hypertension. Out of 3393 patients, 1912 (56.35\%) were females while 1481 (43.65\%) were males. The mean SBP was $130.84 \pm 29.64 \mathrm{mmHg}$, while the mean DBP was $82.65 \pm 19.36 \mathrm{mmHg}$. Means and standard deviation of indicators of obesity are shown in Table 1.

\begin{tabular}{|c|c|c|}
\hline Indicators of Obesity & Mean & Standard Deviation \\
\hline Waist circumference (WC) & $102.85 \mathrm{~cm}$ & $18.14 \mathrm{~cm}$ \\
\hline Hip circumference & $100.33 \mathrm{~cm}$ & $11.81 \mathrm{~cm}$ \\
\hline Weight & $66.93 \mathrm{~kg}$ & $14.92 \mathrm{~kg}$ \\
\hline Height & $1.59 \mathrm{~m}$ & $0.159 \mathrm{~m}$ \\
\hline Waist to hip ratio (WHR) & 1.02 & 0.102 \\
\hline Body mass index (BMI) & $26.37 \mathrm{~kg} / \mathrm{m}^{2}$ & $5.86 \mathrm{~kg} / \mathrm{m}^{2}$ \\
\hline
\end{tabular}

\section{TABLE 1: Means and standard deviation of indicators of obesity}

cm: centimeters; kg: kilograms; m: meters; kg/m2: kilograms per meter square.

Gender of the patient was not associated significantly with hypertension $(\mathrm{p}=0.35)$. However, hypertension was found to be strongly associated with increasing age. Type 2 DM patients belonging to middle and older age groups were more likely to hypertensive as compared to the younger age group (74-76\% versus $41.7 \%$, OR 4.5 , $\mathrm{p}<0.001$ ). Central obesity was found in $80.7 \%$ and $94.7 \%$ of type 2 DM patients according to the WC and WHR cutoff, respectively. Hypertension was significantly associated with all the obesity indicators $(\mathrm{p}<0.001)$. Type 2 DM patients with a high WHR were more likely to be hypertensive as compared to those with normal WHR (75\% versus 65\%, odds ratio (OR) 1.6, p<0.001). A higher than normal WC was also significantly associated with hypertension (79\% versus $56 \%$, OR $2.9, \mathrm{p}<0.001)$. Similarly, obese type $2 \mathrm{DM}$ patients with a BMI $>27 \mathrm{~kg} / \mathrm{m} 2$ were more likely to be hypertensive as compared to those with a BMI of less than 18.5 (83.1\% versus 55.9\%, OR 3.9, p<0.001). Table 2 shows the association of age, gender and different parameters of obesity with hypertension in patients with type $2 \mathrm{DM}$. 


\section{Cureus}

\begin{tabular}{|c|c|c|c|c|c|}
\hline \multirow[b]{2}{*}{ Variable } & & \multicolumn{3}{|c|}{ Blood Pressure } & \multirow[b]{2}{*}{$\mathrm{P}$ value } \\
\hline & & Normotensive N(\%) & Hypertensive $\mathrm{N}(\%)$ & Odds ratio & \\
\hline \multirow{6}{*}{ Age (years) } & $18-20$ & 21 (58.3\%) & $15(41.7 \%)$ & 1 & \multirow{6}{*}{$<0.001$} \\
\hline & $21-30$ & $93(36.8 \%)$ & $160(63.2 \%)$ & 2.4 & \\
\hline & $31-40$ & $268(25.9 \%)$ & $765(74.1 \%)$ & 4 & \\
\hline & $41-50$ & $426(24.0 \%)$ & 1346 (76.0\%) & 4.4 & \\
\hline & $51-60$ & $256(23.7 \%)$ & 822 (76.3\%) & 4.5 & \\
\hline & $>60$ & 99 (25.8\%) & $285(74.2 \%)$ & 4 & \\
\hline \multirow{2}{*}{ Gender } & Female & $637(25.0 \%)$ & 1912 (75.0\%) & 1 & \multirow{2}{*}{0.35} \\
\hline & Male & $526(26.2 \%)$ & 1481 (73.8\%) & 0.9 & \\
\hline \multirow{2}{*}{ WC $(\mathrm{cm})$} & Normal & $383(43.6 \%)$ & $496(56.4 \%)$ & 1 & \multirow{2}{*}{$<0.001$} \\
\hline & High & $780(21.2 \%)$ & 2897 (78.8\%) & 2.9 & \\
\hline \multirow{2}{*}{ WHR } & Normal & $86(35.4 \%)$ & $157(64.6 \%)$ & 1 & \multirow{2}{*}{$<0.001$} \\
\hline & High & 1077 (25.0\%) & 3236 (75.0\%) & 1.6 & \\
\hline \multirow{4}{*}{ BMI $\left(\mathrm{kg} / \mathrm{m}^{2}\right)$} & $<18.5$ & $113(44.1 \%)$ & $143(55.9 \%)$ & 1 & \multirow{4}{*}{$<0.001$} \\
\hline & $18.5-22.99$ & $339(35.6 \%)$ & $614(64.4 \%)$ & 1.4 & \\
\hline & $23-26.99$ & $392(26.9 \%)$ & 1064 (73.1\%) & 2.1 & \\
\hline & $\geq 27$ & 319 (16.9\%) & 1572 (83.1\%) & 3.9 & \\
\hline
\end{tabular}

TABLE 2: Association of age, gender, and different parameters of obesity with hypertension in patients with type 2 diabetes mellitus (DM)

WC: waist circumference; WHR: waist to hip ratio; BMI: body mass index; cm: centimeters.

\section{Discussion}

In our study, the mean age of type 2 diabetic patients was $47.72 \pm 10.82$ years which is lower than similar studies done in the West and Middle East [10-12]. This may be attributed to dietary habits, genetics, and other environmental factors. Our study indicates a high prevalence of hypertension in females (75\%) as compared to males (73.8\%) but it was not statistically significant. This result is different from other studies. In a study conducted in Brazil, hypertension was found to be more prevalent in males (34\%) as compared to females (30.8\%) [13]. Similar results of high prevalence of hypertension in males were found in studies conducted in Argentina, China, and England [14-16]. The difference could be because of multiple factors involving presence or absence of diabetes, socioeconomic status, differences in educational status and environmental factors. This needs to be further investigated. Another important finding in our study was a significant association of hypertension with age. In our 
study, as soon as the patient enters the middle age group and beyond that, the prevalence of hypertension ranges from $74 \%$ to $76 \%$. No statistically significant difference in prevalence is found in the middle age and old age group of diabetics in our study. However, when compared to young age, the difference becomes significant ( $74 \%$ versus $41 \%$, OR $4, \mathrm{p}<0.001)$. This is in contrast with the data obtained from National Health and Nutrition Examination Survey where $70 \%$ of the older patients have hypertension in contrast to $32 \%$ of the patients whose ages were between $40-59$ years [17].

Our study indicated a statistically significant association of hypertension with all the obesity indicators. In our study, $83.1 \%$ of the patients who had high BMI ( $\geqslant 27)$ were found to be hypertensive. Similar results were found in a cross-sectional study conducted on type 2 diabetic patients. In that study where obesity was defined as BMI $\geqslant 30 \mathrm{~kg} / \mathrm{m} 2,86.2 \%$ were found to be hypertensive [10]. Another obesity indicator used in our study was WC. The WC of $\geqslant 90 \mathrm{~cm}$ in men and $\geqslant 80 \mathrm{~cm}$ in women were considered to be obese. In our study, $78.8 \%$ of patients with high WC were hypertensive as compared to $56.4 \%$ with normal WC. This was comparable to another study in which abdominal obesity was defined as WC of $\geqslant 102 \mathrm{~cm}$ in men and $\geqslant 88 \mathrm{~cm}$ in women. That study found $81.5 \%$ of obese patients to be hypertensive as compared to $63.3 \%$ non-obese [10]. Similar results were also found in studies conducted in Sweden and Jordan [1112]. Another indicator defined in our study was WHR. Seventy-five percent of patients with high WHR were found to be hypertensive as compared to $64.6 \%$ with normal WHR. There is not much data found regarding the use of WHR as an obesity indicator in relation to hypertension in type 2 diabetic patients. But there are multiple studies showing a strong association of WHR with hypertension in general population [18-19].

This study had some limitations. It was carried out at a tertiary care center so it may not represent the general population. It was conducted in a single center (diabetic outdoor of Nishtar Hospital Multan, Pakistan). Multi-center studies should be done to further explore this topic.

\section{Conclusions}

Diabetes affects people from all walks of life. It is a global health issue and has become a challenge especially in developing countries like Pakistan. Our study showed that DM is more prevalent in females and middle age groups. There was an alarmingly high prevalence of hypertension and obesity in type 2 DM patients in our study. Again, females were more likely to have hypertension as compared to male diabetics. Central obesity was a more worrisome problem as it affected more than $80 \%$ of diabetics in our study. A very strong association was observed between obesity and hypertension in type 2 DM patients. Hypertension was significantly associated ( $\mathrm{p}<0.001$ ) with all the parameters of obesity (WC, WHR, and $\mathrm{BMI}$ ). Hypertension was also found to be more prevalent in middle and old age diabetics as compared to young type 2 DM patients. Awareness and education in society are of immense importance if we are to control the growing problems of obesity and hypertension in type 2 diabetes patients.

\section{Additional Information \\ Disclosures}

Human subjects: Consent was obtained by all participants in this study. Institutional Ethical review Committee, Nishtar Medical College \& Hospital, Multan issued approval 10904-10. Animal subjects: All authors have confirmed that this study did not involve animal subjects or tissue. Conflicts of interest: In compliance with the ICMJE uniform disclosure form, all authors declare the following: Payment/services info: All authors have declared that no financial support was received from any organization for the submitted work. Financial relationships: All authors have declared that they have no financial relationships at present or 
within the previous three years with any organizations that might have an interest in the submitted work. Other relationships: All authors have declared that there are no other relationships or activities that could appear to have influenced the submitted work.

\section{Acknowledgements}

We acknowledge the work of whole team of Diabetes Clinic Nishtar Hospital Multan.

\section{References}

1. Lascar N, Brown J, Pattison H, Barnett AH, Bailey CJ, Bellary S: Type 2 diabetes in adolescents and young adults. Lancet Diabetes Endocrinol. 2018, 6:69-80. 10.1016/s2213-8587(17)30186-9

2. Scheen AJ: Pathophysiology of type 2 diabetes . Acta Clin Belg. 2003, 58:335-341. 10.1179/acb.2003.58.6.001

3. Leitner DR, Frühbeck G, Yumuk V, Schindler K, Micic D, Woodward E, Toplak H: Obesity and type 2 diabetes: two diseases with a need for combined treatment strategies - EASO can lead the way. Obes Facts. 2017, 10:483-492. 10.1159/000480525

4. Mogre V, Abedandi R, Salifu ZS: Prevalence of obesity and systemic hypertension among diabetes mellitus patients attending an out-patient diabetes clinic in a Ghanaian Teaching Hospital. Diabetes Metab Syndr. 2014, 8:67-71. 10.1016/j.dsx.2014.04.036

5. Epstein M, Sowers JR: Diabetes mellitus and hypertension. Hypertension. 1992, 19:403-418. 10.1161/01.hyp.19.5.403

6. Whelton PK, Carey RM, Aronow WS, et al.: 2017 ACC/AHA/AAPA/ABC/ACPM/AGS/APhA/ASH/ASPC/NMA/PCNA guideline for the prevention, detection, evaluation, and management of high blood pressure in adults: a report of the American College of Cardiology/American Heart Association Task Force on clinical practice guidelines. J Am Coll Cardiol. 2018, 71:127-248. 10.1016/j.jacc.2017.11.006

7. WHO Expert Consultation: Appropriate body-mass index for Asian populations and its implications for policy and intervention strategies. Lancet. 2004, 363:157-63. 10.1016/S01406736(03)15268-3

8. Tan CE, Ma S, Wai D, Chew SK, Tai ES: Can we apply the National Cholesterol Education Program Adult Treatment Panel definition of the metabolic syndrome to Asians?. Diabetes Care. 2004, 27:1182-6. 10.2337/diacare.27.5.1182

9. Snehalatha C, Viswanathan V, Ramachandran A: Cutoff values for normal anthropometric variables in asian Indian adults. Diabetes Care. 2003, 26:1380-4. 10.2337/diacare.26.5.1380

10. Anari R, Amani R, Latifi SM, Veissi M, Shahbazian H: Association of obesity with hypertension and dyslipidemia in type 2 diabetes mellitus subjects. Diabetes Metab Syndr. 2017, 11:37-41. 10.1016/j.dsx.2016.07.004

11. Ridderstråle M, Gudbjörnsdottir S, Eliasson B, Nilsson PM, Cederholm J: Obesity and cardiovascular risk factors in type 2 diabetes: results from the Swedish National Diabetes Register. J Intern Med. 2006, 259:314-322. 10.1111/j.1365-2796.2006.01617.x

12. Mubarak FM, Froelicher ES, Jaddou HY, Ajlouni KM: Hypertension among 1000 patients with type 2 diabetes attending a national diabetes center in Jordan. Ann Saudi Med. 2008, 28:34651. 10.5144/0256-4947.2008.346

13. Alves RF, Faerstein E: Educational inequalities in hypertension: complex patterns in intersections with gender and race in Brazil. Int J Equity Health. 2016, 15:146. 10.1186/s12939-016-0441-6

14. Díaz A, Ferrante D: Trends in prevalence of hypertension in Argentina in the last 25 years: a systematic review of observational studies. Rev Panam Salud Publica. 2015, 38:496-503.

15. Wang J, Zhang L, Wang F, Liu L, Wang H: Prevalence, awareness, treatment, and control of hypertension in China: results from a national survey. Am J Hypertens. 2014, 27:1355-61. 10.1093/ajh/hpu053

16. Joffres M, Falaschetti E, Gillespie C, et al.: Hypertension prevalence, awareness, treatment and control in national surveys from England, the USA and Canada, and correlation with stroke and ischaemic heart disease mortality: a cross-sectional study. BMJ Open. 2013, 3:003423. 10.1136/bmjopen-2013-003423

17. Buford TW: Hypertension and aging. Ageing Res Rev. 2016, 26:96-111. 


\section{Cureus}

10.1016/j.arr.2016.01.007

18. Lin S, Cheng TO, Liu X, et al.: Impact of dysglycemia, body mass index, and waist-to-hip ratio on the prevalence of systemic hypertension in a lean Chinese population. Am J Cardiol. 2006, 97:839-42. 10.1016/j.amjcard.2005.09.133

19. Nemesure B, Wu SY, Hennis A, Leske MC: The relationship of body mass index and waist-hip ratio on the 9-year incidence of diabetes and hypertension in a predominantly African-origin population. Ann Epidemiol. 2008, 18:657-63. 10.1016/j.annepidem.2008.02.006 